\title{
Exoproteome analysis of Clostridium cellulovorans in natural soft-biomass degradation
}

\author{
Kohei Esaka', Shunsuke Aburaya' ${ }^{1}$, Hironobu Morisaka ${ }^{1,2}$, Kouichi Kuroda ${ }^{1}$ and Mitsuyoshi Ueda ${ }^{1,2^{*}}$
}

\begin{abstract}
Clostridium cellulovorans is an anaerobic, cellulolytic bacterium, capable of effectively degrading various types of soft biomass. Its excellent capacity for degradation results from optimization of the composition of the protein complex (cellulosome) and production of non-cellulosomal proteins according to the type of substrates. In this study, we performed a quantitative proteome analysis to determine changes in the extracellular proteins produced by $C$. cellulovorans for degradation of several types of natural soft biomass. C. cellulovorans was cultured in media containing bagasse, corn germ, rice straw (natural soft biomass), or cellobiose (control). Using an isobaric tag method and a liquid chromatograph equipped with a long monolithic silica capillary column/mass spectrometer, we identified 372 proteins in the culture supernatant. Of these, we focused on 77 saccharification-related proteins of both cellulosomal and non-cellulosomal origins. Statistical analysis showed that 18 of the proteins were specifically produced during degradation of types of natural soft biomass. Interestingly, the protein Clocel_3197 was found and commonly involved in the degradation of every natural soft biomass studied. This protein may perform functions, in addition to its known metabolic functions, that contribute to effective degradation of natural soft biomass.
\end{abstract}

Keywords: Clostridium cellulovorans; Cellulosome; Soft-biomass degradation; Proteome analysis; Monolithic column

\section{Introduction}

Cellulosic and herbaceous types of biomass (soft biomass) such as rice straw, switchgrass, and bagasse show promise as substrates for the production of chemical products and fuels. However, it is difficult to degrade soft biomass (Lynd et al. 1999). Cellulose is comprised of a glucose-linked structure that is resistant to degradation due to the number of hydrogen bonds in its crystalline structure (Mansfield et al. 1999). Chemical procedures, including processing with strong acids, high pressures, or high temperatures, are generally employed to degrade cellulose to glucose; however, these methods impose an environmental burden. In addition, degradation strategies must be optimized according to the type of soft biomass, based on individual structures and components.

The artificial and commercial cellulase cocktails currently available are expensive; however, several naturally occurring microbes present an attractive alternative. We have focused on the cellulolytic bacterium Clostridium

\footnotetext{
* Correspondence: miueda@kais.kyoto-u.ac.jp

'Division of Applied Life Sciences, Graduate School of Agriculture, Kyoto University, Sakyo-ku, Kyoto, Japan

${ }^{2}$ Kyoto Integrated Science and Technology Bio-Analysis Center, Shimogyo-ku, Kyoto, Japan
}

\section{Springer}

(C) 2015 Esaka et al.; licensee Springer. This is an Open Access article distributed under the terms of the Creative Commons Attribution License (http://creativecommons.org/licenses/by/4.0), which permits unrestricted use, distribution, and reproduction in any medium, provided the original work is properly credited. cellulovorans. C. cellulovorans is a mesophilic, anaerobic bacterium that can degrade various components of plant cell walls, including not only cellulose, but also hemicelluloses and pectin (Sleat et al. 1984). Previously, we performed genome analysis of C. cellulovorans and demonstrated that it produced a "cellulosome" (Tamaru et al. 2010), a multi-enzyme complex that is known to be produced by several types of cellulolytic and anaerobic bacteria (Bae et al. 2013; Bayer et al. 2004; Doi and Kosugi 2004) such as C. thermocellum (Lamed et al. 1983b; Bayer et al. 1983; Lamed et al. 1983a) and C. cellulolyticum (Desvaux 2005; Gal et al. 1997). C. cellulovorans has high cellulolytic activity due to the presence of numerous polysaccharide degradationrelated proteins that show synergistic effects (Fierobe et al. 2002). Genomic analysis of C. cellulovorans indicated the presence of 57 cellulosome-related genes, including four scaffold and 53 cellulosomal protein-encoding genes (Tamaru et al. 2010). The major scaffold protein, CbpA, is composed of nine cohesin domains that bind to various cellulosomal proteins (Tamaru 2001). Using proteome analysis, we reported that C. cellulovorans optimized the composition of its cellulosomal protein according to the 
type of basal substrates (cellobiose, avicel, and xylan) (Morisaka et al. 2012), and that this ability played a major role in polysaccharide degradation (Matsui et al. 2013). However, compared to the genomes of other cellulosome-producing clostridial species, the genome of C. cellulovorans contains a very large number (190) of non-cellulosomal protein-encoding genes (Tamaru et al. 2011). Non-cellulosomal proteins do not form a complex (cellulosome) and function as free saccharificationrelated enzymes. We reported that non-cellulosomal proteins also played a key role in effective degradation of basal biomass (Matsui et al. 2013). C. cellulovorans could effectively degrade various types of natural soft biomass via the cooperative activity of cellulosomal and non-cellulosomal proteins. This unique and cooperative feature offers the potential to enhance the efficiency of soft-biomass degradation. However, few comprehensive and molecular studies of the degradation of natural soft biomass have been reported. To improve the efficiency of soft-biomass utilization, it will be useful to study the changes in the C. cellulovorans protein profile in response to various types of natural soft biomass.

In this study, we performed a quantitative analysis of the cellulosomal and non-cellulosomal proteins produced by C. cellulovorans during the degradation of several types of natural soft biomass. We used bagasse (the byproduct of sugar cane processing), corn germ (corn embryos), and rice straw as carbon sources. Proteins in the culture supernatant (exoproteome) were analyzed using a LC-MS/MS system equipped with a long monolithic silica capillary column $(470 \mathrm{~cm})$, as described previously (Matsui et al. 2013; Morisaka et al. 2012). We identified the individual protein profiles of the exoproteomes, including both cellulosomal and non-cellulosomal proteins. Additionally, integrated proteome and genome analysis indicated that $C$. cellulovorans produced proteins that showed promise for improving the efficiency of degradation of natural soft biomass.

\section{Methods}

\section{Cell culture and medium}

C. cellulovorans 743B (ATCC35296) was grown anaerobically as previously described (Sleat et al. 1984), differing only in carbon source, which was replaced by $0.3 \%$ $(\mathrm{w} / \mathrm{v})$ cellobiose and $0.3 \%(\mathrm{w} / \mathrm{v})$ soft biomass.

\section{Growth substrates}

Cellobiose (Sigma, St Louis, MO, USA) and cellulosic soft biomass were used in the growth experiments. Bagasse, corn germ, and rice straw were used as soft biomass. Bagasse, containing $39.6 \%$ cellulose, $20.2 \%$ hemicellulose, $25.9 \%$ lignin, $14.3 \%$ other components, was provided by $\mathrm{H}$. Nonaka, Mie University (Nonaka et al. 2013; Ren and Funaoka 2009); corn germ, containing $10.9 \%$ cellulose,
$23.3 \%$ hemicellulose, $0.6 \%$ lignin, $65.2 \%$ other components, was provided by Tsuji Oil Mill Co. Ltd (Furuya et al. 2010); and rice straw (Nakanishi et al. 2012), containing 39.2\% cellulose, $27.4 \%$ hemicellulose, $4.4 \%$ lignin, $29.0 \%$ other components, was provided by $\mathrm{H}$. Miyake, Mie University. These were crushed for $1 \mathrm{~min}$ by using a Hi-Power Blender MX1100XTS (Waring Commercial, Torrington, CT, USA), and the resulting soft biomass (diameter $<250 \mu \mathrm{m}$ ) was used for C. cellulovorans culture.

\section{Preparation of extracellular proteins (exoproteome) for quantitative proteome analysis}

Samples from C. cellulovorans cultures were prepared for proteome analysis as previously described (Matsui et al. 2013). Each stationary-phase culture $(50 \mathrm{~mL})$ was centrifuged $\left(6,000 \times g, 25^{\circ} \mathrm{C}\right)$, and the supernatant was subjected to ultrafiltration using an Amicon Ultra-15 Centrifugal Filter Unit (MWCO $10 \mathrm{kDa}$, Millipore, Darmstadt, Hessen, Germany) to obtain the extracellular proteins. The concentrated samples were independently dissolved in $100 \mu \mathrm{L}$ of triethylammonium bicarbonate buffer $(200 \mathrm{mM})$, to which $5 \mu \mathrm{L}$ of Tris(2-carboxyethyl) phosphine $(200 \mathrm{mM})$ was added, and the reaction was allowed to proceed for $60 \mathrm{~min}$ at $55^{\circ} \mathrm{C}$. To this mixture, $5 \mu \mathrm{L}$ of iodoacetamide $(375 \mathrm{mM})$ was added, and the reaction continued for $30 \mathrm{~min}$, protected from light, at room temperature. Sequencing grade modified trypsin $(1 \mu \mathrm{g} / \mu \mathrm{L}$; Promega, Madison, WI, USA) was added $(2 \mu \mathrm{L})$, and the proteins were digested overnight at $37^{\circ} \mathrm{C}$. The four proteome samples (cellobiose, bagasse, corn germ, and rice straw) were labeled using a tandem mass tag (TMT) 6-plex labeling kit (Thermo Fisher Scientific, Waltham, MA, USA) with reporters at $m / z=128,129,130$, and 131, respectively, in $41 \mu \mathrm{L}$ acetonitrile. After $60 \mathrm{~min}$ of reaction at room temperature, $8 \mu \mathrm{L}$ of $5 \%(\mathrm{w} / \mathrm{v})$ hydroxylamine was added to each tube and mixed for $15 \mathrm{~min}$. In addition, a mixture of tryptic fragments from all substrates was combined with TMT-126 (reporter at $m / z=126$ ) as an internal standard for quantification. The aliquots were then pooled and evaporated under vacuum and dissolved in $100 \mu \mathrm{L}$ of trifluoroacetic acid $(0.1 \%)$ and used for LC-MS/MS analysis.

\section{Exoproteome analysis}

Proteome analysis was performed using an LC (Ultimate $3000^{\circ}$; Thermo Fisher Scientific)-MS/MS (LTQ Orbitrap Velos Mass Spectrometer ${ }^{\circ}$; Thermo Fisher Scientific) system equipped with a long monolithic column, as previously described (Matsui et al. 2013; Morisaka et al. 2012). Tryptic digests were separated by reversed-phase chromatography using a monolithic silica capillary column

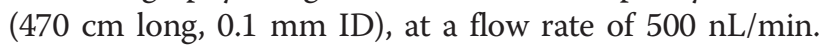
The gradient was provided by changing the mixing ratio of the two eluents: A, $0.1 \%(\mathrm{v} / \mathrm{v})$ formic acid and B, $80 \%$ acetonitrile containing $0.1 \%(\mathrm{v} / \mathrm{v})$ formic acid. The 
gradient was started with $5 \% \mathrm{~B}$, increased to $45 \%$ B for $600 \mathrm{~min}$, further increased to $95 \% \mathrm{~B}$ to wash the column, returned to the initial condition, and held for reequilibration. The separated analytes were detected using a mass spectrometer with a full scan range of $350-1,500 \mathrm{~m} / \mathrm{z}$ (resolution 60,000 ), followed by 10 datadependent higher-energy c-trap dissociation (HCD) MS/MS scans acquired for TMT reporter ions, using $40 \%$ normalized collision energy in HCD with $0.1 \mathrm{~ms}$ activation time and an electrospray ionization (ESI) voltage of $2.3 \mathrm{kV}$. The ion transfer tube temperature was set to $280^{\circ} \mathrm{C}$. Triplicate analyses were performed for each sample in three independent experiments, and the collected data were reviewed for protein identification and quantification.
Data analysis was performed using Proteome Discoverer software (Thermo Fisher Scientific). Protein identification was performed using the Mascot algorithm against the C. cellulovorans protein database $(4,254$ sequences) from NCBI (National Center for Biotechnology Information, http://www.ncbi.nlm.nih.gov/), with a precursor mass tolerance of $20 \mathrm{ppm}$ and a fragment ion mass tolerance of $50 \mathrm{mmu}$. Carbamidomethylation of cysteine and a TMT 6-plex at the N-terminus were set as fixed modifications. Protein quantification was performed using the Reporter Ions Quantifier with the TMT 6-plex method. The data were then filtered with a cut-off criteria of $q$-value $\leq 0.05$, corresponding to a $5 \%$ false discovery rate (FDR) on a spectral level. The values for the exponentially modified protein abundance index
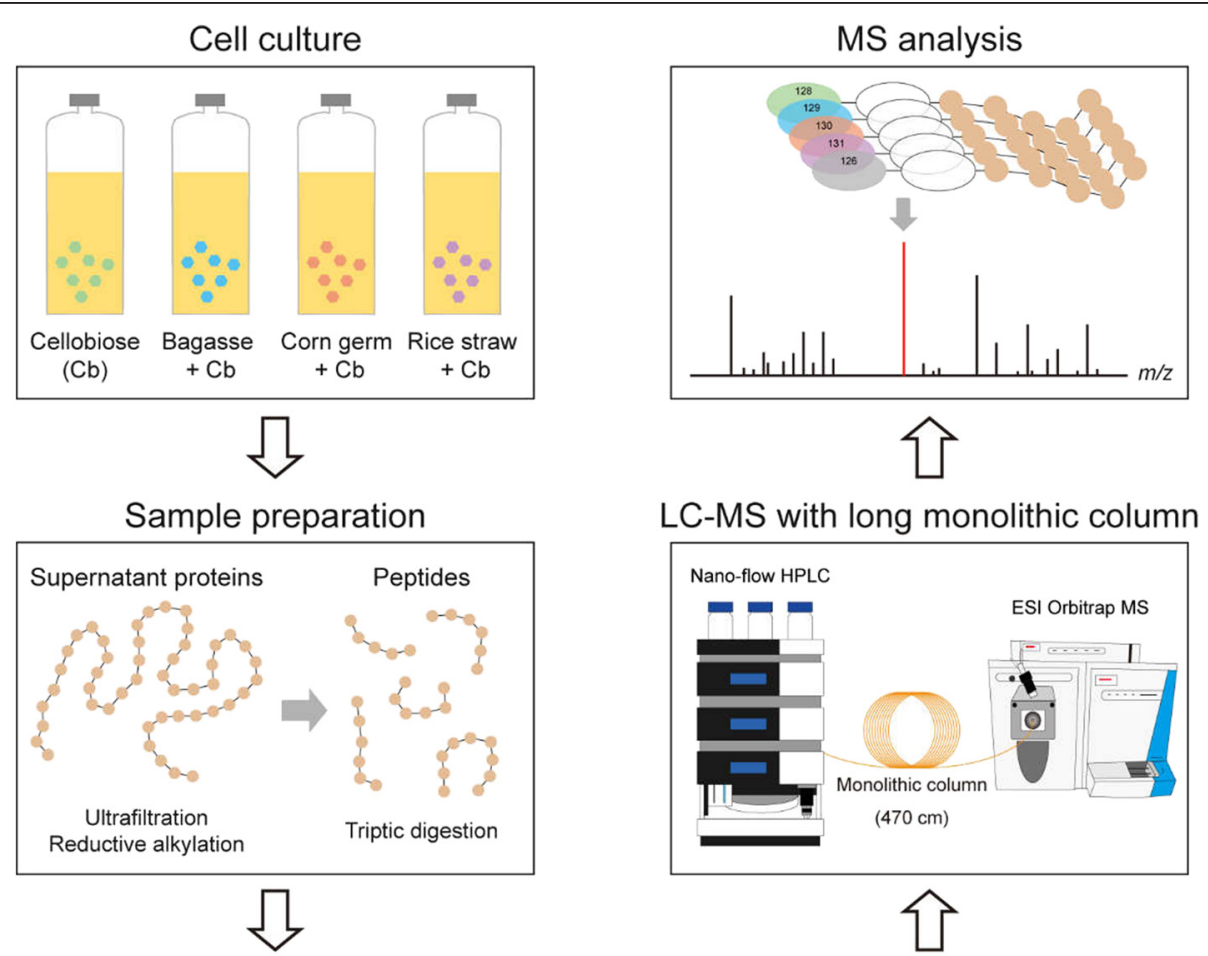

\section{LC-MS with long monolithic column}

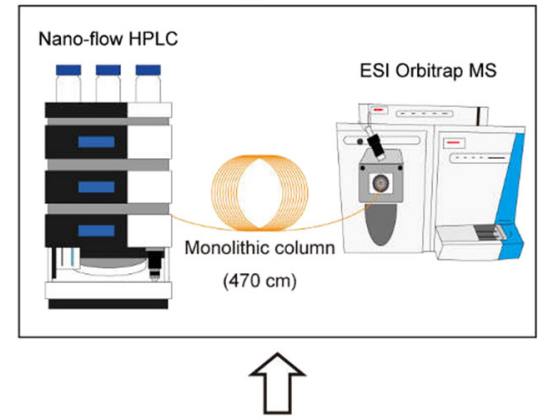

TMT labeling
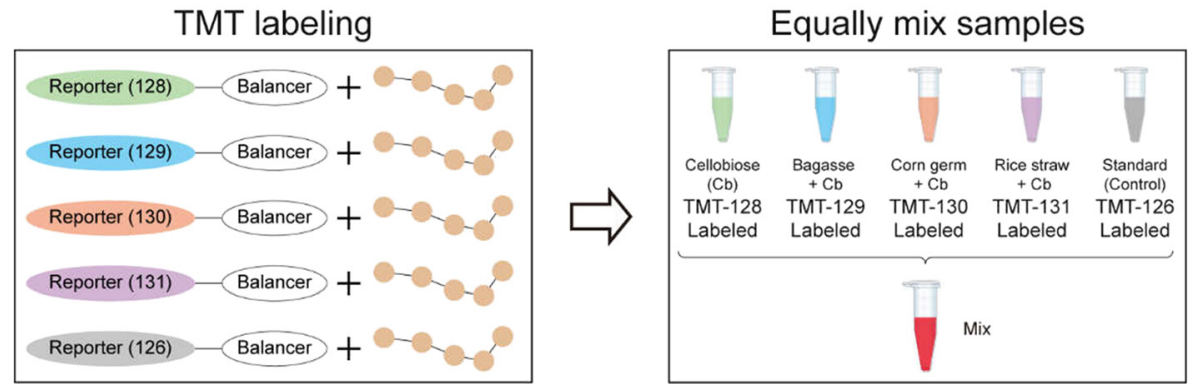

Figure 1 Experimental procedure for C. cellulovorans exoproteome analysis. Proteome analysis was performed as previously described (Matsui et al. 2013). Proteins in the culture supernatant of C. cellulovorans grown in the presence of cellobiose (Cb), bagasse, corn germ, or rice straw were individually reductive-alkylated and digested with trypsin, and tryptic fragments were labeled with tandem mass tags (TMTs). The labeled peptides were mixed and injected into the LC-MS/MS system with a long monolithic column for mass measurement, and the data collected were used for protein quantification. 
(emPAI) (Ishihama et al. 2005) were used to estimate the abundance of cellulosomal and non-cellulosomal proteins. Proteins with no missing values in three replicates were accepted in the protein quantification analysis. Global median normalization was performed to normalize the quantity of each tryptic digest injected into the mass spectrometer.

\section{Results}

\section{Analysis of proteins in C. cellulovorans culture supernatants}

To investigate the degradation of natural soft biomass, proteins were isolated from the supernatant of stationaryphase C. cellulovorans cultures grown on bagasse, corn germ, or rice straw, and subjected to LC-MS/MS analysis (Figure 1) (Matsui et al. 2013). The mass spectrometry data collected were used for exoproteome analysis, as shown in Figure 2.

To normalize the amount of each tryptic digest injected into the mass spectrometer, the identified proteins were standardized with the median. To determine which proteins were differentially produced for each type of soft biomass, we focused on 77 cellulosomal and non-

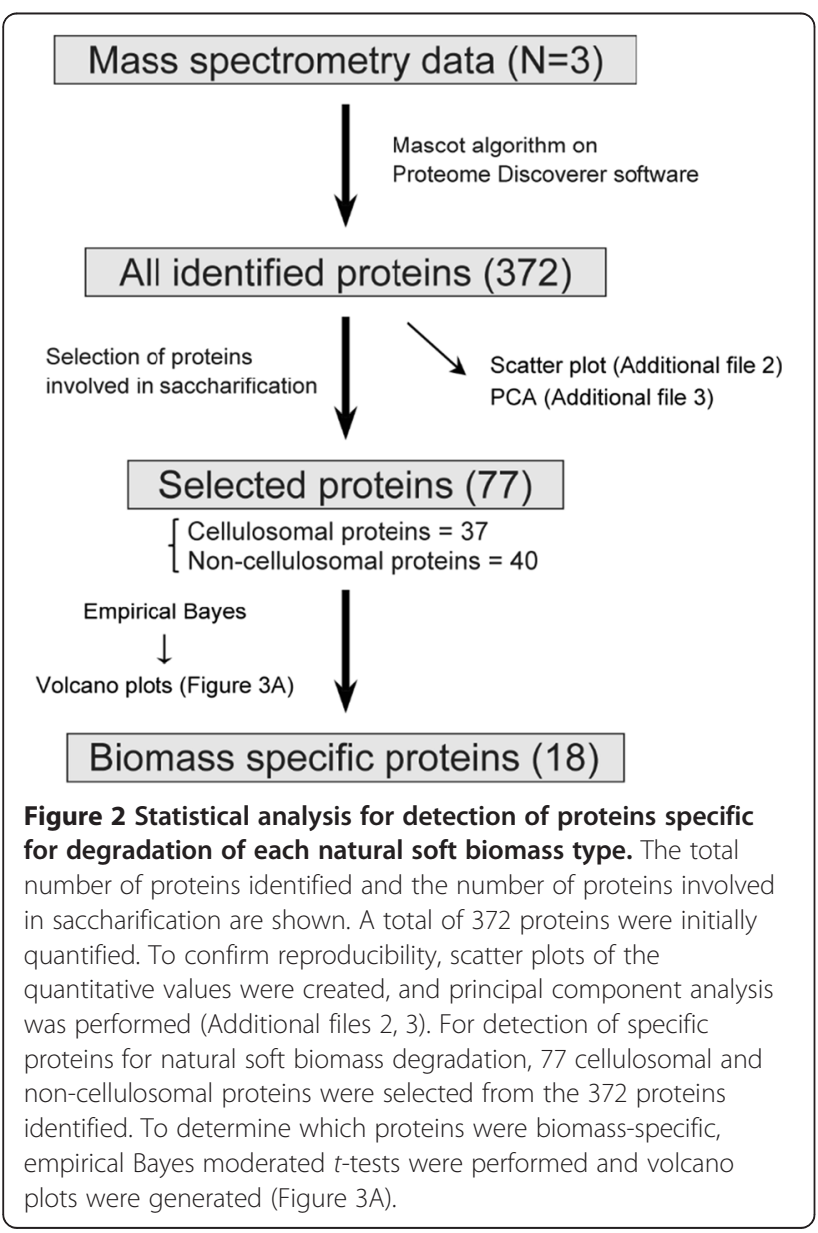

cellulosomal saccharification-related enzymes, chosen from among the 372 proteins identified (Additional file 1). Next, we performed empirical Bayes moderated $t$-tests and created volcano plots (Figure 3A) using the quantitative values for each of the 77 proteins (Matsui et al. 2013); proteins produced in culture with cellobiose were used as controls. P-values were adjusted using the Benjamini-Hochberg method to avoid the problem of multiple testing. Proteins which met the criteria (FDRadjusted $P$-value $<0.05$ and fold-change of protein ratio $>$ 2 as compared to cellobiose) were defined as individual "biomass-specific proteins." Four bagasse-, 11 corn germ-, and six rice straw-specific proteins were identified (Figure 3B and Table 1).

\section{Bagasse-specific proteins}

Four bagasse-specific proteins were identified, including one cellulosomal and three non-cellulosomal proteins. The cellulosomal protein was Clocel_2820 (HbpA), a scaffolding protein with no enzymatic activity, similar to CbpA, which is the main scaffolding protein of the cellulosome. HbpA has been reported to enhance cellulosomal cellulase (Clocel_1150 (EngB) or Clocel_2819 (EngL)) activity on solid substrates such as avicel or corn fiber, but not on soluble carboxymethyl cellulose (Matsuoka et al. 2007). Thus, C. cellulovorans might increase the production of HbpA to accelerate cellulase activity on solid biomass. Among the non-cellulosomal proteins, Clocel_0873, which is classified as a member of the PL9 family by the Carbohydrate-Active enZymes (CAZy) database (Lombard et al. 2014), is considered to have pectate lyase activity. Clocel_1430, classified as a member of the GH31 family, is considered to have $\alpha$-xylosidase activity. Clocel_0873 is a pectin-specific protein, and Clocel_1430 is a xylan-specific protein (Matsui et al. 2013). C. cellulovorans might recognize the pectin contained in bagasse and produce these proteins in response. Clocel_3197, a member of the GH130 family, was also detected.

\section{Corn germ-specific proteins}

One cellulosomal protein, Clocel_3650, and 10 non-cellulosomal proteins were identified. Clocel_3650, a member of the GH44 family, is considered to have endoglucanase activity. Among the non-cellulosomal proteins, Clocel_2606, classified as a member of the GH5 and CBM46 families, is considered to have cellulose-binding as well as cellulose-degrading activities (Aspeborg et al. 2012); it is a phosphoric acid swollen cellulose (PASC)specific protein (Matsui et al. 2013). Clocel_3650 and Clocel_2606 are considered to be involved in acceleration of cellulose degradation. Clocel_0034, a member of the GH31 family, is considered to have $\alpha$-xylosidase activity, while Clocel_2535, classified as a member of the GH43 family, is considered to have $\beta$-xylosidase 


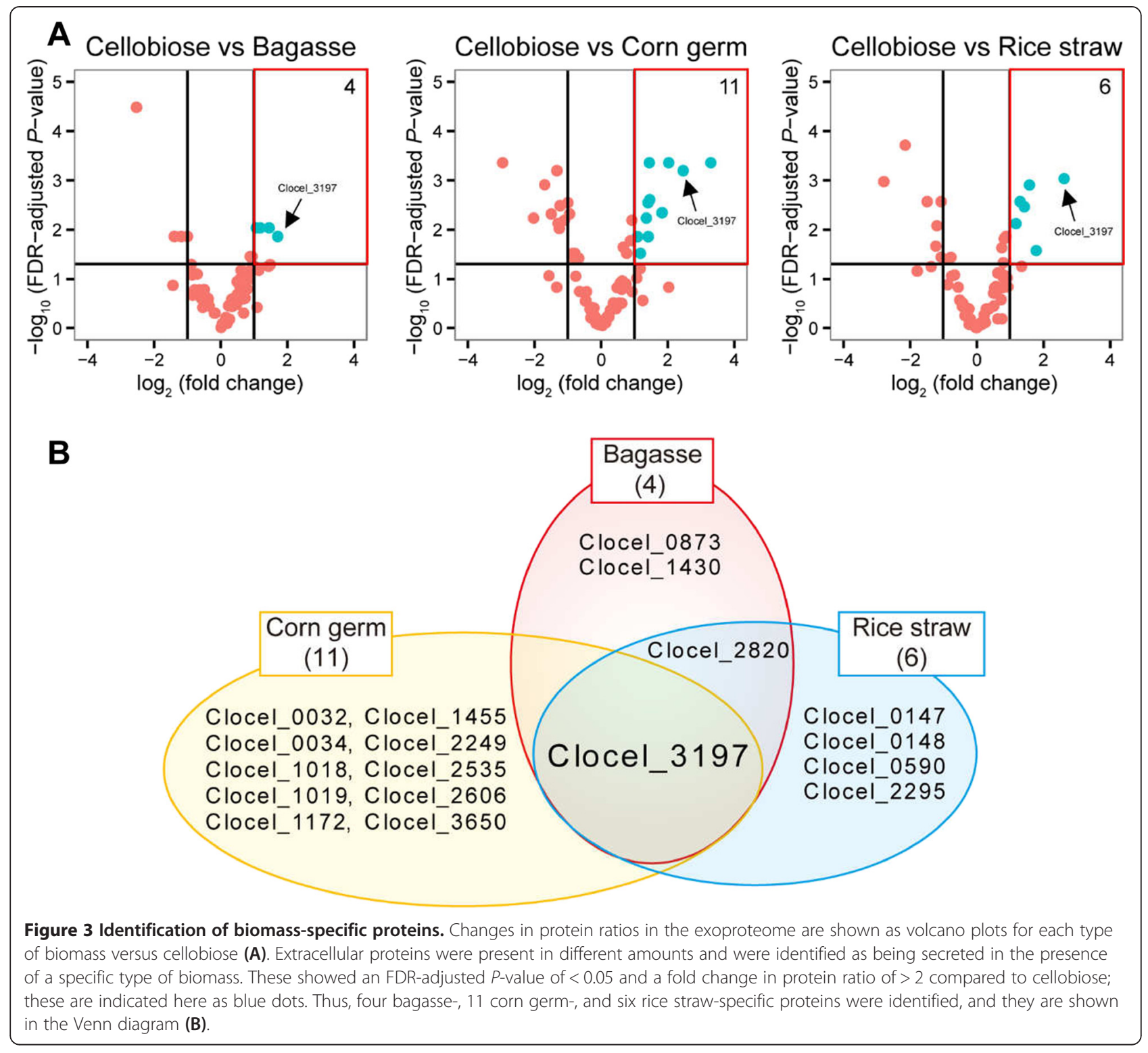

activity. These xylan degradation-related proteins are thought to contribute to the acceleration of xylan degradation. Clocel_1455, a member of the GH53 and CBM61 families, is considered to have endo-1, 4- $\beta$ galactosidase activity and 1, 4- $\beta$-galactan binding ability (Cid et al. 2010). Clocel_0032 is also a PASC-specific protein (Matsui et al. 2013). It is a member of the GH94 family and is considered to have cellodextrin phosphorylase activity. Clocel_1172 is a pectin-specific protein (Matsui et al. 2013). It is a member of the PL1 family and is thought to have pectate lyase activity. Clocel_2249 is considered to be a glucuronate isomerase, and it also contributes to the acceleration of pectin degradation. Clocel_1018 and Clocel_1019 are members of the GH1 family; enzymes in this family are thought to have various enzymatic activities, such as $\beta$-glucosidase and $\beta$-xylosidase activities. Clocel_3197, which was identified among the bagasse-specific proteins, was also detected.

\section{Rice straw-specific proteins}

The rice straw-specific proteins consisted of four cellulosomal and two non-cellulosomal proteins. Among the cellulosomal proteins, Clocel_2295 (XynA), a member of the GH11 and CE4 families, has endoxylanase and acetyl-xylan esterase activities (Kosugi et al. 2002) and is a xylan-specific protein (Matsui et al. 2013). Since xylan (xylose) is abundant in the hemicellulose of rice straw (Yoswathana et al. 2010), C. cellulovorans is considered to recognize xylose and increase the production of XynA for effective degradation of rice straw. Clocel_0147 is a cysteine protease inhibitor (Meguro et al. 2011), which is 
Table 1 The list of biomass-specific proteins

\begin{tabular}{|c|c|c|c|c|c|c|c|}
\hline \multirow{2}{*}{$\begin{array}{l}\text { Biomass } \\
\text { specifically }\end{array}$} & \multirow[t]{2}{*}{ Protein type } & \multirow[t]{2}{*}{ Locus } & \multirow[t]{2}{*}{ Name $^{a}$} & \multirow[t]{2}{*}{ CAZy family(ies) ${ }^{b}$} & \multicolumn{2}{|l|}{ vs Cellobiose } & \multirow[t]{2}{*}{ emPAI } \\
\hline & & & & & $\log _{2}$-fold change & FDR-adjusted $P$-value ${ }^{c}$ & \\
\hline \multirow[t]{4}{*}{ Bagasse (4) } & Cellulosomal & Clocel_2820 & $\mathrm{HbpA}$ & NA & 1.45 & $9.13 \mathrm{E}-03$ & 2.49 \\
\hline & Non-cellulosomal & Clocel_1430 & & $\mathrm{GH} 31$ & 1.19 & $9.13 \mathrm{E}-03$ & 0.55 \\
\hline & & Clocel_3197 & & GH130 & 1.71 & $1.37 \mathrm{E}-02$ & 0.79 \\
\hline & & Clocel_0873 & & PL9 & 1.07 & $9.13 \mathrm{E}-03$ & 1.19 \\
\hline \multirow[t]{11}{*}{ Corn germ (11) } & Cellulosomal & Clocel_3650 & & $\mathrm{GH} 44$ & 1.45 & 4.39E-04 & 0.53 \\
\hline & Non-cellulosomal & Clocel_1018 & & $\mathrm{GH} 1$ & 1.41 & $2.85 \mathrm{E}-03$ & 0.77 \\
\hline & & Clocel_1019 & & $\mathrm{GH} 1$ & 3.29 & 4.39E-04 & 0.34 \\
\hline & & Clocel_2606 & & GH5,CBM46 & 1.36 & $5.78 \mathrm{E}-03$ & 2.44 \\
\hline & & Clocel_0034 & & $\mathrm{GH} 31$ & 1.46 & $2.48 \mathrm{E}-03$ & 0.51 \\
\hline & & Clocel_2535 & & $\mathrm{GH} 43$ & 1.09 & $1.38 \mathrm{E}-02$ & 0.20 \\
\hline & & Clocel_1455 & & GH53,CBM61,CBM61,CBM61 & 2.03 & 4.39E-04 & 0.13 \\
\hline & & Clocel_0032 & & $\mathrm{GH} 94$ & 1.83 & $4.50 \mathrm{E}-03$ & 0.36 \\
\hline & & Clocel_3197 & & $\mathrm{GH} 130$ & 2.46 & $6.34 \mathrm{E}-04$ & 0.79 \\
\hline & & Clocel_1172 & & PL1 & 1.41 & $1.38 \mathrm{E}-02$ & 0.50 \\
\hline & & Clocel_2249 & & NA & 1.18 & 3.00E-02 & 1.01 \\
\hline \multirow[t]{6}{*}{ Rice straw (6) } & Cellulosomal & Clocel_2295 & XynA & GH11,CE4 & 1.79 & $2.64 \mathrm{E}-02$ & 0.69 \\
\hline & & Clocel_0148 & & NA & 1.59 & $1.24 \mathrm{E}-03$ & 0.65 \\
\hline & & Clocel_0147 & CpiA & NA & 1.3 & $2.72 \mathrm{E}-03$ & 9.10 \\
\hline & & Clocel_2820 & $\mathrm{HbpA}$ & NA & 1.43 & $3.46 \mathrm{E}-03$ & 2.49 \\
\hline & Non-cellulosomal & Clocel_3197 & & GH130 & 2.63 & $9.16 \mathrm{E}-04$ & 0.79 \\
\hline & & Clocel_0590 & & NA & 1.19 & 7.51E-03 & 5.27 \\
\hline
\end{tabular}

${ }^{a}$ Name: Names of only the reported proteins were shown.

bee http://www.cazy.org/. NA, not annotated (not included in CAZy database).

${ }^{c} P$-values were adjusted for multiple testing with the Benjamini-Hochberg method.

demPAl: the values of exponentially modified protein abundance index.

considered to protect microbe and their cellulosomes from plant protease attack. Our results suggest that $C$. cellulovorans recognizes rice as its substrate and produces large amounts of cyspin as a defense mechanism. Clocel_0148, a protein of unknown function, was identified as a rice straw-specific protein. Clocel_2820 (HbpA), found among the bagasse-specific proteins, was also detected. Clocel_0590, detected among the non-cellulosomal proteins, is thought to be a xylose isomerase (Ota et al. 2013) and to be involved in degradation of the xylan contained in rice straw. Clocel_3197, found in both the bagasse- and corn germ-specific proteins, was also detected.

\section{Discussion}

We identified several proteins involved in degradation of various types of biomass; analysis of replicates showed that the results were reproducible. Scatter plots of normalized quantitative values for all combinations showed high correlation factors (Additional file 2). Principal component analysis (PCA) was performed for all 372 identified proteins to confirm that the proteome profile was similar between three biological replicates. The PCA score plots (Additional file 3) showed a degree of high similarity between biological replicates, and the plots for each substrate formed individual groups. These results indicate that the quantitative proteome analysis showed a high degree of reproducibility and reliability.

Of the total 372 proteins identified, 77 proteins were determined to be involved in saccharification. Of these, 37 were cellulosomal proteins and 40 were non-cellulosomal proteins (Additional file 1). C. cellulovorans possesses 57 cellulosomal protein-encoding genes and 190 noncellulosomal protein-encoding genes. Therefore, $C$. cellulovorans produced $64.9 \%$ (37 of 57) of its cellulosomal proteins and $21.1 \%$ (40 of 190) of its non-cellulosomal proteins for degradation of the types of natural soft biomass examined here.

From the statistical analysis, Clocel_3197 was commonly identified as all biomass-specific proteins in $C$. cellulovorans exoproteome. Interestingly, SignalP analysis did not detect a signal peptide-encoding sequence for Clocel_3197. Clocel_3197 is likely to be localized to the exterior of cells, based on the emPAI of Clocel_3197, which was nearly equal to that of Clocel_2295 (XynA) 
(Table 1), which has a signal peptide-encoding sequence. This result also indicated that sample preparation did not lyse cells. Clocel_3197, a member of the GH130 family, has been annotated as a D-fructose 4-o- $\beta$-Dmannosyl-D-glucose phosphorylase. Some species, such as Bacteroides fragilis, have the homologue of Clocel_3197 containing operon and it plays an important role in mannan catabolic pathway (Senoura et al. 2011). However, all enzymes related to mannan degradation or metabolism were not detected (Additional file 1). Thus, this protein may also possess an extracellular function. Previous reports have indicated the presence of several proteins lacking signal peptides that are secreted by unconventional pathways (López-Villar et al. 2006; Kinseth et al. 2007). For example, several metabolites produced by Clocel_3197, which have different functions like those observed in moon-lighting proteins (Kinseth et al. 2007; López-Villar et al. 2006) may play an important role during substrate recognition and natural soft-biomass degradation by $C$. cellulovorans. The mechanisms of substrate degradation and recognition remain unknown, and this protein may be useful in future investigations of the substrate degradation and recognition mechanisms of $C$. cellulovorans.

In conclusion, we quantified the cellulosomal and noncellulosomal protein profiles produced by $C$. cellulovorans cultured on various types of soft biomass. A total of 77 cellulosomal and non-cellulosomal proteins were identified from the C. cellulovorans culture supernatant by using an LCMS/MS system equipped with a long monolithic silica capillary column. Empirical Bayes moderated $t$-tests and volcano plots identified four bagasse-, 11 corn germ-, and six rice straw-specific proteins. Clocel_3197 was identified from the supernatant of cultures grown on all three types of biomass, and may perform as-yet-unknown functions that contribute to effective degradation of natural soft biomass.

\section{Additional files}

Additional file 1: The $\mathbf{3 7 2}$ proteins identified. Proteome analytes were injected to LC-MS/MS system. Collected data were used for protein identification by Proteome Discoverer software. Three independent biological experiments were performed, and proteins identified in every replicates with a number of used peptides per protein $(\geq 3)$ were accepted. As a result, 372 proteins were successfully identified.

Additional file 2: Scatter plots of the three biological replicates for each substrate. The fold-change values of identified 372 proteins (Additional file 1) by using the Reporter lons Quantifier with the TMT 6-plex method were normalized using global median. Scatter plots of normalized values were depicted using the data derived from three biological replicates of each culture (cellobiose, bagasse, corn germ, and rice straw). The values of Pearson's correlation were successfully high in each combination.

Additional file 3: Principal component analysis of the data from the three biological replicates. Principal component analysis was performed using normalized fold-change values of identified 372 proteins (Additional file 1) for investigation of the similarity of protein production profile between each biological replicate. Proteome data from each substrate clustered in close proximity. The cumulative contribution rate for principal component (PC) PC1 to PC3 was $87.5 \%$ (green: cellobiose; red: bagasse; purple: corn germ; blue: rice straw).

\section{Abbreviations}

ATCC: American type culture collection CAZy, carbohydrate-active enZymes; Cb: Cellobiose; CBM: Carbohydrate-binding modules;

CE: Carbohydrate esterases; Cyspin: Cystein protease inhibitor;

emPAl: Exponentially modified protein abundance index; ESI: Electrospray ionization; FDR: False discovery rate; GH: Glycoside hydrolases; GT: Glycosyl transferases; HCD: Higher-energy c-trap dissociation; HPLC: High performance liquid chromatography; ID: Internal diameter; LC-MS: Liquid chromatographymass spectrometry; NCBI: National Center for Biotechnology Information; PCA: Principal component analysis; PL: Polysaccharide lyases;

PMI: Phosphomannose isomerase; PASC: Phosphoric acid swollen cellulose; SDS: Sodium sodecyl sulfate; TMT: Tandem mass tag.

\section{Competing interests}

The authors declare that they have no competing interest.

\section{Authors' contributions}

KE and SA generated the strains used. KE, SA and HM performed most of the mass measurement. KE, SA and HM performed most of the statistical analyses. KE, HM, KK and MU designed the study and drafted the manuscript. All authors read and approved the final manuscript.

\section{Acknowledgements}

We thank Dr. Hiroshi Nonaka, Dr. Hideo Miyake (Mie University), and Tsuji Oil Mill Co. Ltd. for kindly providing soft biomass. We thank Mr. Daisuke Higo

(Thermo Fisher Scientific) for valuable discussion for mass spectrometry. This research was supported by JST, CREST. This work was also partially supported by the Program for Promotion of Basic and Applied Researches for Innovations in Bio-oriented Industry (BRAIN).

Received: 21 November 2014 Accepted: 23 December 2014

Published online: 24 January 2015

\section{References}

Aspeborg H, Coutinho PM, Wang Y, Brumer H, Henrissat B (2012) Evolution, substrate specificity and subfamily classification of glycoside hydrolase family 5 (GH5). BMC Evol Biol 12(1):186

Bae J, Morisaka H, Kuroda K, Ueda M (2013) Cellulosome complexes: natural biocatalysts as arming microcompartments of enzymes. J Mol Microbiol Biotechnol 23(4-5):370-378

Bayer EA, Kenig R, Lamed R (1983) Adherence of Clostridium thermocellum to cellulose. J Bacteriol 156(2):818-827

Bayer EA, Belaich J-P, Shoham Y, Lamed R (2004) The cellulosomes: multienzyme machines for degradation of plant cell wall polysaccharides. Annu Rev Microbiol 58:521-554

Cid M, Pedersen HL, Kaneko S, Coutinho PM, Henrissat B, Willats WG, Boraston AB (2010) Recognition of the helical structure of $\beta-1,4-$ galactan by a new family of carbohydrate-binding modules. J Biol Chem 285(46):35999-36009

Desvaux M (2005) The cellulosome of Clostridium cellulolyticum. Enzyme Microb Technol 37(4):373-385

Doi RH, Kosugi A (2004) Cellulosomes: plant-cell-wall-degrading enzyme complexes. Nat Rev Microbiol 2(7):541-551

Fierobe HP, Bayer EA, Tardif C, Czjzek M, Mechaly A, Belaich A, Lamed R, Shoham Y, Belaich JP (2002) Degradation of cellulose substrates by cellulosome chimeras substrate targeting versus proximity of enzyme components. J Biol Chem 277(51):49621-49630

Furuya H, Ide Y, Hamamoto M, Asanuma N, Hino T (2010) Isolation of a novel bacterium, Blautia glucerasei sp. nov., hydrolyzing plant glucosylceramide to ceramide. Arch Microbiol 192(5):365-372

Gal L, Pages S, Gaudin C, Belaich A, Reverbel-Leroy C, Tardif C, Belaich J-P (1997) Characterization of the cellulolytic complex (cellulosome) produced by Clostridium cellulolyticum. Appl Environ Microbiol 63(3):903-909

Ishihama Y, Oda Y, Tabata T, Sato T, Nagasu T, Rappsilber J, Mann M (2005) Exponentially modified protein abundance index (emPAl) for estimation of 
absolute protein amount in proteomics by the number of sequenced peptides per protein. Mol Cell Proteomics 4(9):1265-1272

Kinseth MA, Anjard C, Fuller D, Guizzunti G, Loomis WF, Malhotra V (2007) The Golgi-associated protein GRASP is required for unconventional protein secretion during development. Cell 130(3):524-534

Kosugi A, Murashima K, Doi RH (2002) Xylanase and acetyl xylan esterase activities of XynA, a key subunit of the Clostridium cellulovorans cellulosome for xylan degradation. Appl Environ Microbiol 68(12):6399-6402

Lamed R, Setter E, Bayer E (1983a) Characterization of a cellulose-binding, cellulasecontaining complex in Clostridium thermocellum. J Bacteriol 156(2):828-836

Lamed R, Setter E, Kenig R, Bayer E (1983b) The cellulosome: a discrete cell surface organelle of Clostridium thermocellum which exhibits separate antigenic, cellulosebinding and various cellulolytic activites. Biotechnol Bioeng Symp 13:163-181

Lombard V, Ramulu HG, Drula E, Coutinho PM, Henrissat B (2014) The carbohydrate-active enzymes database (CAZy) in 2013. Nucleic Acids Res 42(D1):D490-D495

López-Villar E, Monteoliva L, Larsen MR, Sachon E, Shabaz M, Pardo M, Pla J, Gil C, Roepstorff P, Nombela C (2006) Genetic and proteomic evidences support the localization of yeast enolase in the cell surface. Proteomics 6(S1):S107-S118

Lynd LR, Wyman CE, Gerngross TU (1999) Biocommodity engineering. Biotechnol Prog 15(5):777-793

Mansfield SD, Mooney C, Saddler JN (1999) Substrate and enzyme characteristics that limit cellulose hydrolysis. Biotechnol Prog 15(5):804-816

Matsui K, Bae J, Esaka K, Morisaka H, Kuroda K, Ueda M (2013) Exoproteome profiles of Clostridium cellulovorans grown on various carbon sources. Appl Environ Microbiol 79(21):6576-6584

Matsuoka S, Yukawa H, Inui M, Doi RH (2007) Synergistic interaction of Clostridium cellulovorans cellulosomal cellulases and HbpA. J Bacteriol 189(20):7190-7194

Meguro H, Morisaka H, Kuroda K, Miyake H, Tamaru Y, Ueda M (2011) Putative role of cellulosomal protease inhibitors in Clostridium cellulovorans based on gene expression and measurement of activities. J Bacteriol 193(19):5527-5530

Morisaka H, Matsui K, Tatsukami Y, Kuroda K, Miyake H, Tamaru Y, Ueda M (2012) Profile of native cellulosomal proteins of Clostridium cellulovorans adapted to various carbon sources. AMB Express 2(1):1-5

Nakanishi A, Bae J, Fukai K, Tokumoto N, Kuroda K, Ogawa J, Nakatani M, Shimizu S, Ueda M (2012) Effect of pretreatment of hydrothermally processed rice straw with laccase-displaying yeast on ethanol fermentation. Appl Microbiol Biotechnol 94(4):939-948

Nonaka H, Kobayashi A, Funaoka M (2013) Lignin isolated from steam-exploded eucalyptus wood chips by phase separation and its affinity to Trichoderma reesei cellulase. Bioresour Technol 140:431-434

Ota M, Sakuragi H, Morisaka H, Kuroda K, Miyake H, Tamaru Y, Ueda M (2013) Display of Clostridium cellulovorans xylose isomerase on the cell surface of Saccharomyces cerevisiae and its direct application to xylose fermentation. Biotechnol Prog 29(2):346-351

Ren H, Funaoka M (2009) Potential of herbaceous lignocellulosics as industrial raw materials. Trans Materials Res Soc Japan 34(4):727-730

Senoura T, Ito S, Taguchi H, Higa M, Hamada S, Matsui H, Ozawa T, Jin S, Watanabe J, Wasaki J (2011) New microbial mannan catabolic pathway that involves a novel mannosylglucose phosphorylase. Biochem Biophys Res Commun 408(4):701-706

Sleat R, Mah RA, Robinson R (1984) Isolation and characterization of an anaerobic, cellulolytic bacterium, Clostridium cellulovorans sp. nov. Appl Environ Microbiol 48(1):88-93

Tamaru Y (2001) The Clostridium cellulovorans cellulosome: an enzyme complex with plant cell wall degrading activity. Chem Rec 1(1):24-32

Tamaru Y, Miyake H, Kuroda K, Nakanishi A, Kawade Y, Yamamoto K, Uemura M, Fujita Y, Doi RH, Ueda M (2010) Genome sequence of the cellulosome-producing mesophilic organism Clostridium cellulovorans 743B. J Bacteriol 192(3):901-902

Tamaru Y, Miyake H, Kuroda K, Nakanishi A, Matsushima C, Ueda M (2011) Comparison of the mesophilic cellulosome-producing Clostridium cellulovorans genome with other cellulosome-related clostridial genomes. Microb Biotechnol 4(1):64-73

Yoswathana N, Phuriphipat P, Treyawutthiwat P, Eshtiaghi MN (2010) Bioethanol production from rice straw. Energy Res J 1(1):26

\section{Submit your manuscript to a SpringerOpen ${ }^{\odot}$ journal and benefit from:}

- Convenient online submission

$\checkmark$ Rigorous peer review

- Immediate publication on acceptance

- Open access: articles freely available online

- High visibility within the field

- Retaining the copyright to your article

Submit your next manuscript at $>$ springeropen.com 